\title{
Cerebellar Cortex and Cerebellar Nuclei Are Concomitantly Activated during Eyeblink Conditioning: A 7T fMRI Study in Humans
}

\author{
Markus Thürling, ${ }^{1,2}$ Fabian Kahl, ${ }^{1}$ Stefan Maderwald, ${ }^{2}$ Roxana M. Stefanescu, ${ }^{1,2}$ Marc Schlamann, ${ }^{3}$ Henk-Jan Boele, ${ }^{4}$ \\ Chris I. De Zeeuw, ${ }^{4,5}$ ㅇörn Diedrichsen, ${ }^{6}$ Mark E. Ladd, ${ }^{2,7}$ Sebastiaan K. E. Koekkoek, ${ }^{4}$ and Dagmar Timmann ${ }^{1}$ \\ Departments of ${ }^{1}$ Neurology, University Clinic Essen, ${ }^{2}$ Erwin L. Hahn Institute for MRI, and ${ }^{3}$ Diagnostic and Interventional Radiology and Neuroradiology, \\ University Clinic Essen, University of Duisburg-Essen, 45147 Essen, Germany, ${ }^{4}$ Department of Neuroscience, Erasmus University Medical Center, 3000 DR \\ Rotterdam, The Netherlands, ${ }^{5}$ The Netherlands Institute for Neuroscience, Royal Academy of Arts and Sciences, 1105 BA Amsterdam, The Netherlands, \\ 'Institute of Cognitive Neuroscience, University College London, WC1N 3AR London, United Kingdom, and 'Division of Medical Physics in Radiology \\ (E020), German Cancer Research Center, 69120 Heidelberg, Germany
}

There are controversies whether learning of conditioned eyeblink responses primarily takes place within the cerebellar cortex, the interposed nuclei, or both. It has also been suggested that the cerebellar cortex may be important during early stages of learning, and that there is a shift to the cerebellar nuclei during later stages. As yet, human studies have provided little to resolve this question. In the present study, we established a setup that allows ultra-high-field 7T functional magnetic resonance imaging (fMRI) of the cerebellar cortex and interposed cerebellar nuclei simultaneously during delay eyeblink conditioning in humans. Event-related fMRI signals increased concomitantly in the cerebellar cortex and nuclei during early acquisition of conditioned eyeblink responses in 20 healthy human subjects. ANOVAs with repeated-measures showed significant effects of time across five blocks of 20 conditioning trials in the cortex and nuclei $(p<0.05$, permutation corrected). Activations were most pronounced in, but not limited to, lobules VI and interposed nuclei. Increased activations were most prominent at the first time the maximum number of conditioned responses was achieved. Our data are consistent with a simultaneous and synergistic two-site model of learning during acquisition of classically conditioned eyeblinks. Because increased MRI signal reflects synaptic activity, concomitantly increased signals in the cerebellar nuclei and cortex are consistent with findings of learning related potentiation at the mossy fiber to nuclear cell synapse and mossy fiber to granule cell synapse. Activity related to the expression of conditioned responses, however, cannot be excluded.

Key words: acquisition; cerebellum; eyeblink conditioning; fMRI; human; interposed nuclei

\section{Introduction}

Eyeblink conditioning is widely used to understand how the cerebellum contributes to motor learning (for review, see Bracha et al., 2009; Thompson and Steinmetz, 2009). Animal studies show that eyeblink conditioning depends on the integrity of the intermediate cerebellum (Bracha et al., 2001). The relative contribu-

\footnotetext{
Received June 18, 2014; revised Sept. 12, 2014; accepted 0ct. 11, 2014.

Author contributions: M.E.L., S.K.E.K., and D.T. designed research; M.T., F.K., S.M., and D.T. performed research; R.M.S., J.D., and S.K.E.K. contributed unpublished reagents/analytic tools; M.T., F.K., M.S., H.-J.B., and J.D. analyzed data; C.I.D.Z., M.E.L., and D.T. wrote the paper.

This work was supported by Grants of the German Research Foundation given to D.T. and M.E.L. (DFG TI 239/10-1, 10-2) as part of the DFG Research Unit FOR 1581, by Mercator Research Center Ruhr, and by the Marie Curie Initial Training Network "Cerebellar-Cortical Control: Cells, Circuits, Computation and Clinic." H.-J.B., C.I.D.Z., and S.K.E.K. are funded by Dutch Organization for Life Sciences (NWO-ALW), Behavioural Sciences (MaGW), Medical Sciences (ZonMW), and the European Community (ERC-advanced). We thank Siemens Healthcare for providing us with the Works-in-Progress package for fMRI with sinusoidal EPI at ultra-high-field.

The authors declare no competing financial interests.

Correspondence should be addressed to Dr Dagmar Timmann, Department of Neurology, University Clinic Essen, University of Duisburg-Essen, Hufelandstrasse 55, 45147 Essen, Germany. E-mail dagmar.timmann-braun@uni-due.de.

DOI:10.1523/JNEUROSCI.2492-14.2015

Copyright $\odot 2015$ the authors $\quad 0270-6474 / 15 / 351228-12 \$ 15.00 / 0$
}

tions of the cerebellum to the acquisition and expression of conditioned responses are a matter of ongoing discussion (for review, see, e.g., Delgado-García in Manto et al., 2012). There is a longstanding controversy whether learning primarily takes place within the cerebellar cortex ( for review, see Cooke et al., 2004; Longley and Yeo, 2014), the interposed nuclei (for review, see McCormick and Thompson, 1984a; Christian and Thompson, 2003), or both (for review, see Freeman and Steinmetz, 2011). Some findings suggest that the cerebellar cortex may be important during early stages of learning, and that there is a shift to the cerebellar nuclei during later stages (Medina et al., 2002). An active transfer process from the cerebellar cortex to the cerebellar nuclei has also been proposed for adaptation of the vestibuloocular reflex (for review, see Raymond et al., 1996; Kassardjian et al., 2005) and optokinetic nystagmus (Shutoh et al., 2006). Human imaging studies have shown a shift from the cerebellar cortex to the cerebellar nuclei during early motor skill acquisition (Doyon et al., 2002).

As yet human studies have added little to the understanding of the relative contributions of the cerebellar cortex and nuclei to the acquisition of conditioned eyeblink responses. Both studies in 


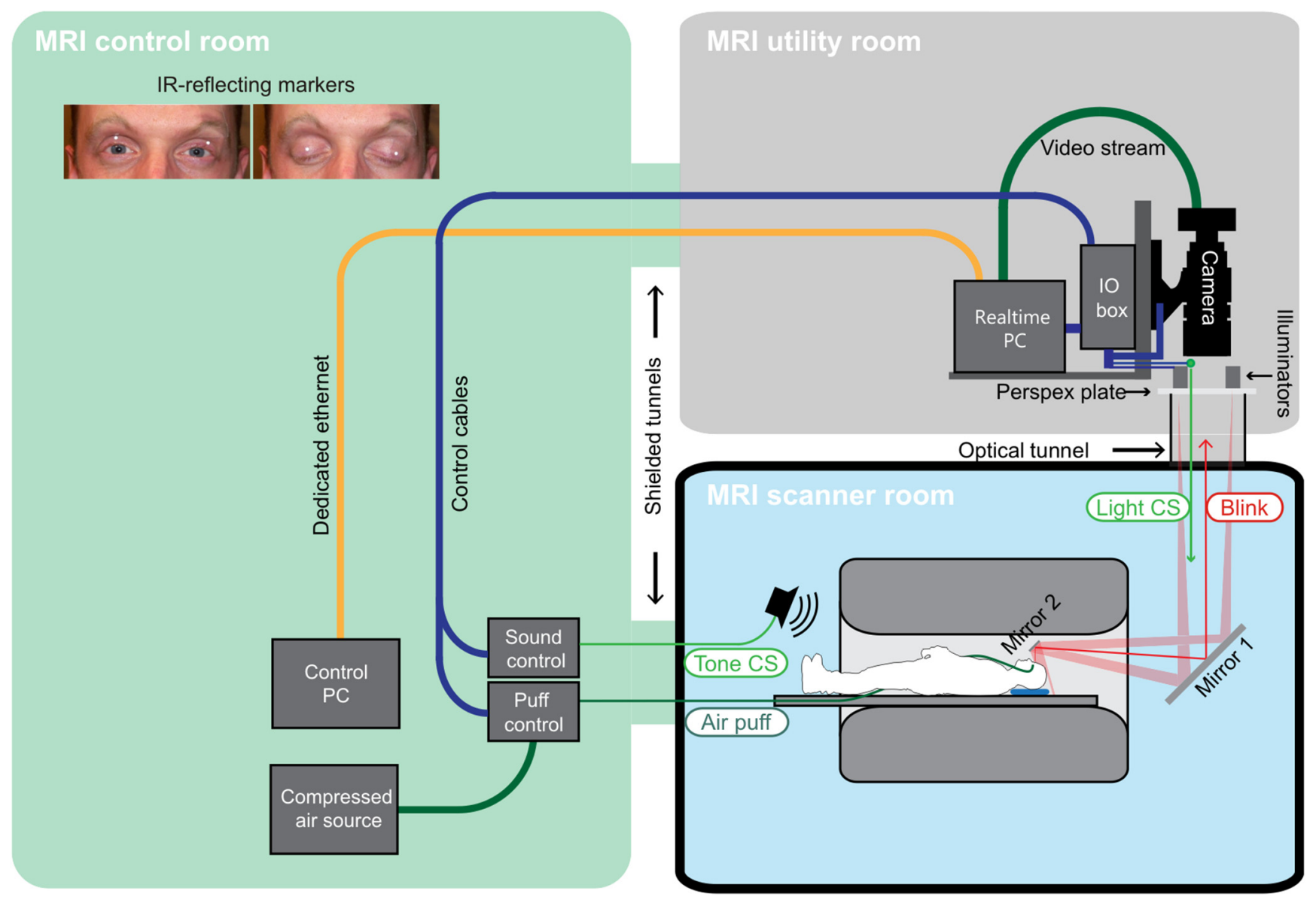

Figure 1. Experimental eyeblink conditioning setup in the 7T MR scanner. Two small infrared light reflecting markers were attached to the eyelids (inset, top-left quadrant). Infrared light was applied via light sources outside the scanner (MRl utility room). Light reached the markers via a mirror system (mirror 1 and mirror 2 in the scanner room). Via the same mirror system, marker movements were recorded using a high-speed video camera that was positioned outside the scanner (MRI utility room). Air compressor and tone sources were located in the MRI control room.

cerebellar patients and functional neuroimaging studies provide good evidence that the cerebellar cortex contributes to acquisition of conditioned eyeblink responses (Ramnani et al., 2000; Gerwig et al., 2003; Dimitrova et al., 2008; Parker et al., 2012). Little is known about the involvement of the nuclei in humans. Human lesion studies are limited because pure lesions of the cerebellar nuclei are a rare exception (Timmann et al., 2009). In functional magnetic resonance imaging (fMRI) studies robust activations of the cerebellar nuclei are difficult to obtain because of their small size and high iron content (Habas, 2010).

A series of recent developments in neuroimaging technologies in our group now provide a powerful tool to address this question, because they allow for simultaneous recordings of activity within the cerebellar cortex and nuclei, even while performing eyeblink conditioning. The introduction of ultra-high-field MRI and the development of optimized normalization methods have made reliable fMRI studies at the level of the dentate nuclei possible (Diedrichsen et al., 2011). In addition, we established a setup to perform and record delay eyeblink conditioning in a 7T MRI scanner in humans using a novel optical approach. Finally, normalization methods were extended to the level of the interposed nuclei.

We tested the hypothesis that early acquisition of conditioned eyeblink responses depends on the cerebellar cortex but not the cerebellar nuclei. Cortical activation was expected to be exclusively present or to precede activation of the nuclei during early acquisition. Findings, however, showed that the cerebellar cortex and interposed nuclei were simultaneously active during early motor learning, which is consistent with their synergistic contribution to the learning process. Potential underlying neuronal mechanisms are discussed based on the existing animal literature and current knowledge of the physiology of the blood oxygenation level-dependent (BOLD) signal.

\section{Materials and Methods}

\section{Participants}

A total of 27 young and healthy subjects participated (mean age: $24.3 \pm$ 3.7 years, range: 19-35 years; 14 male, 13 female). All subjects were right-handed based on the Edinburgh handedness inventory (Oldfield, 1971). Subjects were excluded who did not show significant eyeblink conditioning, defined as a total conditioned response (CR) incidence in paired trials below spontaneous blink rate; for more details see below. Consequently, data of only 20 participants (mean age: $24.2 \pm 4.2$ years, range: $19-35$ years; 9 male, 11 female) were included in statistical group analysis. Informed consent was obtained from all participants. The study was approved by the local ethics committee.

\section{Eyeblink conditioning: experimental setup and data analysis}

The conditioning system was custom-built by Neurasmus (Erasmus Neuroscience, http://www.neurasmus.com/) as part of a scientific collaboration. An optical solution was used to collect eyeblink responses. Two small infrared light reflecting markers (diameter $2.5 \mathrm{~mm}$; Loligo Systems) were attached to the upper eyelids (Fig. 1, inset). Infrared light was applied via light sources ( $5 \mathrm{w}$ CREE Ultrafire $805 \mathrm{~nm}$ ) outside the scanner. Light reached the markers via a two-mirror system with one mirror attached to the head coil and the other at the back of the scanner 

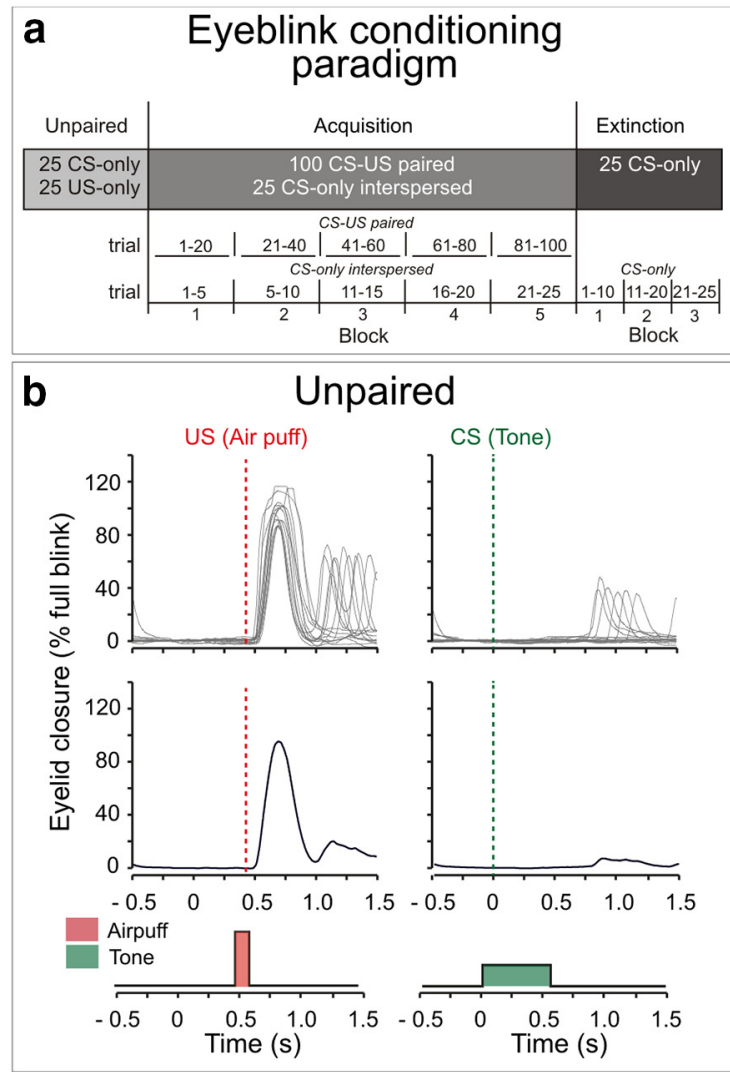
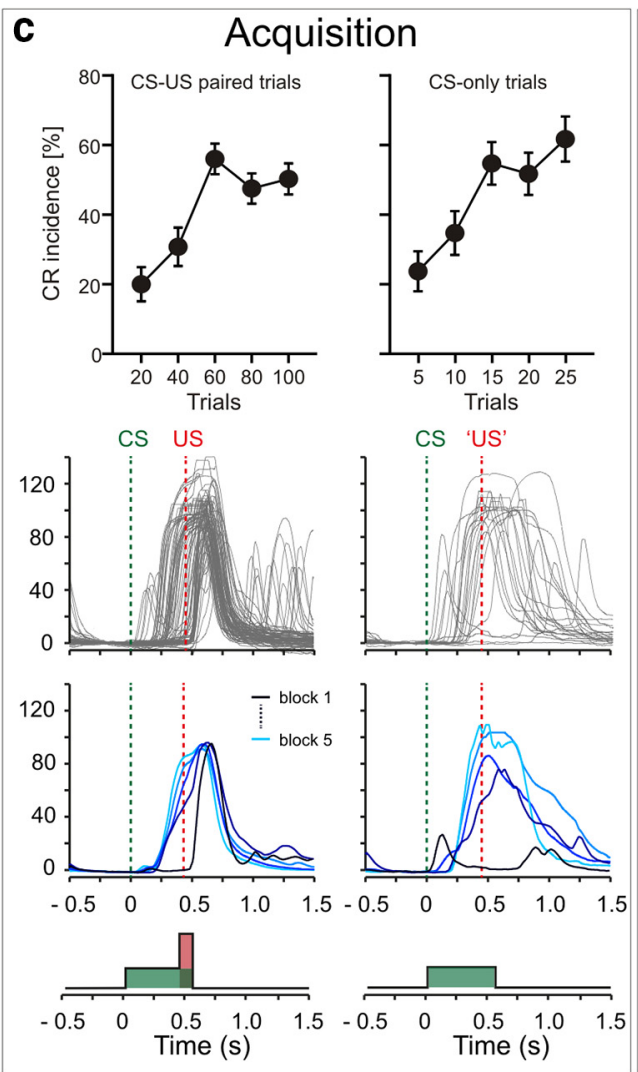
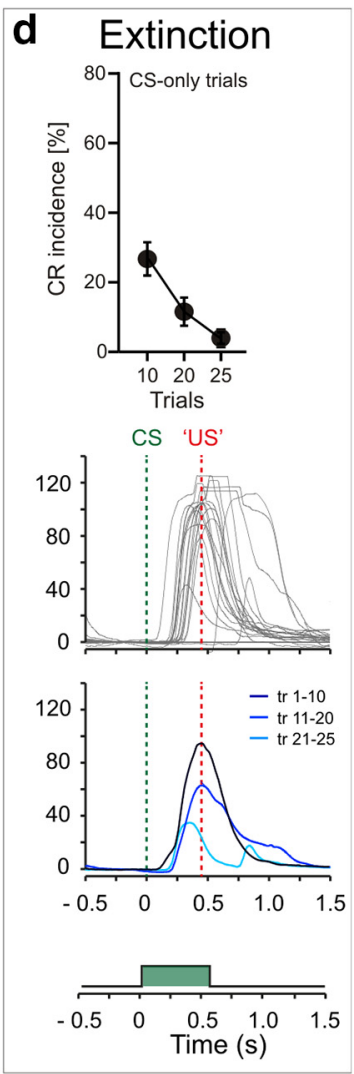

Figure 2. Eyeblink conditioning paradigm ( $\boldsymbol{a}$ ) and behavioral data $(\boldsymbol{b}-\boldsymbol{d})$. Group mean CR incidences and SEs are shown in the top row, individual eyelid traces in the second row, and averaged traces of the same subject in the third row. $\boldsymbol{b}$, Unpaired phase: the tone-CS does not elicit eyeblinks, whereas the air puff-US is consistently followed by eyeblinks. $\boldsymbol{c}$, Acquisition phase: paired CS-US trials are shown on the right and CS-only trials interspersed in paired trials on the left. Conditioned responses which start after CS onset and before US onset are clearly seen. $\boldsymbol{d}$, Extinction phase: CS-only extinction trials are shown in two blocks of 10 trials and one block of five trials. Decline of CR incidence is clearly seen. tr, Trial.

(Fig. 1). Via the same mirror system, marker movements were recorded using a high-speed video camera (Basler A504k). Light sources and video camera were positioned in the room above the scanner. The unconditioned stimulus (US) was an air puff delivered through plastic tubing connected to an air compressor (Neurasmus MCA-2) outside the scanner. The conditioned stimulus (CS) was a tone $(1500 \mathrm{~Hz})$ that could be clearly differentiated from scanner acoustic noise. In addition, an optical CS was used (explained in more detail below) to further ensure successful conditioning despite the scanner acoustic noise.

Eyeblink conditioning was performed using the standard delay protocol developed by Gormezano and Kehoe (1975). The CS preceded the US by a fixed time interval and coterminated with the US. The air puff US (duration $100 \mathrm{~ms} ; 6$ bar at source) was applied through a nozzle fixed to the head of the subject. The nozzle was set to direct the air puff to the outer canthus of the right eye at a distance of $\sim 10 \mathrm{~mm}$. The CS started $500 \mathrm{~ms}$ after onset of each trial and consisted of an initially neutral tone (duration $550 \mathrm{~ms}$ ) and preceded the US by $450 \mathrm{~ms}$. The tone was applied via a loudspeaker which was positioned close to the back of the bore. In addition, a green light was shown continuously in the upper third of the mirror (Fig. 1, mirror 2). The green light was projected via an LED outside the scanner room using the same mirror system as described above. The green light went off at the same time as the tone-CS was on.

An unpaired phase (25 CS-only, 25 US-only; randomized presentation within each subject but not between subjects) was followed by an acquisition phase (100 paired CS-US trials; Fig. 2A). During acquisition, phase 25 CS-only trials were interspersed. At the end of the experiment 25 CS-only extinction trials were presented. The time interval between trials varied between 16, 18, and $20 \mathrm{~s}$ (randomized within each subject, but not between subjects).

One of the two markers attached to the eyelids was tracked online by tracking software provided by Neurasmus. The marker best visible was used. During setup, the marker was outlined by hand, and during the experiment, tracking was automatically performed by the control software (LabVIEW). In short, bitmasks and thresholds set by the experimenter during setup were used to create a binary image that only contains the marker. Center-of-mass coordinates of the marker were calculated frame by frame in real-time and converted into position. Eyelid fully open and closed positions of the marker were used to calibrate the optical signal to percentage of eyelid closure.

Eyeblink recordings were analyzed on a trial-by-trial basis with custom computer software (LabVIEW). Conditioned eyeblink responses were semiautomatically identified within the CS-US interval. Response onset was automatically defined as being where amplitude deviated $3 \mathrm{SDs}$ from the $500 \mathrm{~ms}$ pre-CS baseline level. Trials were visually inspected and implausible CRs were excluded from analysis. Responses earlier than 150 $\mathrm{ms}$ after CS onset were regarded as reflexive responses to the tone (i.e., $\alpha$ responses) and not conditioning-related (Woodruff-Pak et al., 1996). Trials that showed a spontaneous blink before CS onset were excluded from behavioral analysis (Bracha et al., 1997).

The total number of paired trials was subdivided into five blocks (20 trials per block). Interspersed CSs in paired trials were subdivided into five blocks ( 5 trials per block), extinction trials into five blocks ( 5 trials per block) and, for direct comparison with fMRI data, three blocks (2 blocks including 10 trials each and 1 block including 5 trials). The number of CRs was expressed as the percentage of trials containing responses with respect to each block (percentage CR incidence). Repeatedmeasures ANOVAs were used to analyze changes across consecutive blocks; $p<0.05$ was considered significant. Greenhouse Geisser correction was applied when appropriate. To estimate the frequency of spontaneous blinks, responses in the $500 \mathrm{~ms}$ time interval before CS onset were counted in each paired trial and the average rate of spontaneous blinks (blinks per minute) calculated across paired trials. All analyses were performed using SPSS 22.0. 


\section{MRI scanning}

An event-related design was used with four separate fMRI runs (464 scans per run). The first run corresponded to the unpaired phase. The second, third, and first half of the fourth run corresponded to the acquisition phase, and the second half of the fourth run to the extinction phase. Each run lasted 15:36 min. Total time in the scanner was on average 90 min and included a structural scan.

A whole-body 7T MR scanner (Magnetom 7T, Siemens Healthcare) was used to acquire BOLD contrast-weighted echoplanar images (EPIs) for functional scans. Head movements were reduced with the help of wedge-shape bolsters. All fMRI images were acquired with a 32-channel transmit/receive head coil (Nova Medical). Each EPI session consisted of 464 mosaic scans with 33 coronal slices: $\mathrm{TR}=2000 \mathrm{~ms}, \mathrm{TE}=27 \mathrm{~ms}$, field-of-view $(\mathrm{FOV})=220 \times 220 \mathrm{~mm}^{2}$, matrix $110 \times 110$, parallel MRI (pMRI) GRAPPA: $r=2$, TA 15:36 min, bandwidth $1108 \mathrm{~Hz} /$ pixel. The excitation pulse angle was $76^{\circ}$. Voxel size was $2.0 \times 2.0 \times 2.0 \mathrm{~mm}^{3}$ with $10 \%$ distance factor acquired in ascending order. The scans covered the entire cerebellum. The FOV included only parts of the overlying cerebral cortex. The readout gradients were sinusoidal. To avoid ghost artifacts, coronal slices were measured with the phase-encoding direction $F \gg H$ (Thürling et al., 2011). In addition, local instead of global phase correction was used to reduce ghost artifacts. Sinc-shaped radio frequency (RF) excitation pulses were applied to reduce specific absorption rate (both provided by Siemens Healthcare).

The MR trigger signals were used to synchronize application of the CS and US. Test trials were needed for synchronization. Because of magnetization relaxation effects and 1-2 initial test trials, the first 9 or 11 volumes in each run were discarded from further analysis. The Siemens Physiologic Monitoring Unit was used to collect breathing and pulse rate synchronized to MR scanning (www.medical.siemens.com). Pulse oximetry was recorded using a wireless recording device clipped to the subject's index finger. A respiratory bellows was attached to the subject using a belt.

In addition, a three-dimensional (3D) transverse volume of the entire brain was acquired using a T1-weighted magnetization prepared rapid acquisition gradient echo sequence (adiabatic wideband uniform rate smooth truncation pulse-MPRAGE; 176 sagittal slices, TR $=3500 \mathrm{~ms}$, $\mathrm{TE}=1.27 \mathrm{~ms}, \mathrm{TI}=1100 \mathrm{~ms}$, bandwidth $560 \mathrm{~Hz} /$ pixel, $\mathrm{FOV}=256 \times 224$ $\mathrm{mm}^{2}$, pMRI GRAPPA $r=2$, TA 6:15 min, flip angle $6^{\circ}$, slice thickness $=$ $1 \mathrm{~mm}$ with a voxel size of $1 \times 1 \times 1 \mathrm{~mm}^{3}$; Wrede et al., 2012).

\section{Image analysis}

The functional imaging data were analyzed using SPM8 (Wellcome Department of Cognitive Neurology, London, UK) and MATLAB 2011a (MathWorks). Slice timing correction was applied (Eklund et al., 2012). The EPI images were realigned to correct for head motion, resulting in creation of a mean EPI image. The first image was selected as a reference and all images from all paradigms were realigned to this image. The origin was set at the apex of the fourth ventricle. The mean image was then used as a reference image to coregister the realigned functional images to the anatomical T1 image of the individual participant. The default brightness threshold (defaults.mask.thresh) in SPM was changed from 0.8 to 0.1 to avoid signal dropouts within the hypointense cerebellar nuclei. For first level statistical analysis, a general linear model was applied to the realigned and coregistered, but otherwise unsmoothed, EPI images (Friston et al., 1995). The time series of each voxel was fitted with a corresponding task regressor that modeled a boxcar convolved with a canonical hemodynamic response function. A temporal high-pass filter (cutoff $128 \mathrm{~s}$ ) was used to remove the low-frequency drifts in the data, and serial autocorrelations were taken into account by means of an autoregressive model first-order correction [AR(1)]. RETROICOR (retrospective image-based correction) was applied to correct for physiological motion effects (Glover et al., 2000). PhLEM Toolbox (https://sites. google.com/site/phlemtoolbox) and custom-made software written in MATLAB were used to prepare pulse and breathing data as regressors (eight regressors, sine, and cosine of the respiration phase and the cardiac phases).
Mean head movements between scans were $<0.3 \mathrm{~mm}$ for translations and $<0.15^{\circ}$ for rotations in the $x, y$, and $z$ directions for all conditions; maximum head movements were $<4 \mathrm{~mm}$ and $2^{\circ}$.

The active event was modeled with a train of delta functions convolved with the hemodynamic response function. In US-only trials, start was defined at $1000 \mathrm{~ms}$ after the beginning of each scan (duration of $0 \mathrm{~ms}$ ). In paired and CS-only trials, start was defined at $800 \mathrm{~ms}$ after the beginning of each scan. Because onsets of CRs (but not URs) were variable, duration was set as $100 \mathrm{~ms}$. To analyze activity related to the unconditioned response in the unpaired phase, the BOLD effect was analyzed in US-only trials by means of one-sample $t$ tests. The BOLD effect was analyzed in the same way in CS-only trials. To analyze activity related to CR acquisition, a repeated-measures ANOVA was applied (called one-way ANOVA within-subject design in SPM8; http://www.fil.ion.ucl.ac.uk/ wpenny/ publications/rik_anova.pdf). The effect of time was assessed across the five blocks of paired CS-US trials (20 trials per block). In addition, activity related to the first 10 extinction trials was compared with the second 10 extinction trials using a one-way ANOVA within-subject design. Statistical results are reported at a height threshold of $p<$ 0.05 . Permutation tests were used to correct the significance level for multiple comparisons (Winkler et al., 2014). One thousand permutations were applied.

\section{Cerebellar cortex}

For the normalization of the cerebellar cortical data, the T1-weighted images were deformed to fit the spatially unbiased atlas template (SUIT) of the human cerebellum using the SUIT toolbox (v2.7) in SPM8 (http://www.icn.ucl.ac.uk/motorcontrol/imaging/suit.htm; Diedrichsen, 2006). Initially the program isolates the cerebellum and creates a mask. These masks were manually corrected with the help of MRIcronsoftware (http://www.mccauslandcenter.sc.edu/mricro/mricron). This was necessary because parts of the occipital cortex are frequently included when the automated segmentation algorithm is used. SUIT toolbox v2.7 uses the DARTEL-algorithm for normalization (Ashburner, 2007), which deforms the cerebellum to simultaneously fit the probability maps or cortical gray-matter, white matter and deep cerebellar nuclei to an atlas template. Nonlinear deformation was then applied to each contrast image from the individual participants. The normalized images were then smoothed by a three-dimensional convolution with an isotropic Gaussian kernel of $4 \mathrm{~mm}$ full-width at half-maximum (FWHM). The "explicit masking" option was used in SPM. Small volume correction (SVC), based on the probabilistic atlas of the cerebellar cortex, was performed (Diedrichsen et al., 2009).

\section{Dentate and interposed nucleus}

Dentate-interposed template. In a previous study Diedrichsen et al. (2011) introduced a template of the dentate nuclei. Based on the same principles, a new template was created for this study that included both the dentate and interposed nuclei. Susceptibility weighted imaging (SWI) sequences were acquired in a new group of 24 healthy subjects (13 male, 11 female; mean age: $31.8 \pm 6.4$ years, range: $23-44$ years). The same whole-body 7T MR scanner and 32-channel transmit/receive head coil was used as for the fMRI experiments. 144 axial slices were acquired to cover the complete cerebellum: $\mathrm{TR}=50 \mathrm{~ms}, \mathrm{TE}-1=23.5 \mathrm{~ms}$, TE- $2=$ $31.2 \mathrm{~ms}$, BW $160 \mathrm{~Hz} /$ pixel, FOV $=224 \times 182 \mathrm{~mm}^{2}$, matrix $448 \times 364$, pMRI GRAPPA $r=4, \mathrm{TA}=13: 05 \mathrm{~min}$, flip angle $18^{\circ}$, slice thickness 0.5 $\mathrm{mm}$ with a noninterpolated voxel size of $0.5 \times 0.5 \times 0.5 \mathrm{~mm}^{3}$. Two TEs were applied: the shorter TE-1 (23.5 ms) was used to get better information in the iron-richer ventral (macrogyric) part of the dentate, the longer TE-2 $(31.2 \mathrm{~ms})$ to get better information in the iron-poorer dorsal (microgyric) part (Maderwald et al., 2012). In addition, a MPRAGE sequence of the entire head was acquired: 176 axial slices, $\mathrm{TR}=3500 \mathrm{~ms}$, $\mathrm{TE}=3.71 \mathrm{~ms}, \mathrm{TI}=1100 \mathrm{~ms}, \mathrm{BW} 200 \mathrm{~Hz} /$ pixel, FOV $=256 \times 176 \mathrm{~mm}^{2}$, matrix $256 \times 176$, pMRI GRAPPA $r=4$, TA 4:38 min, flip angle $8^{\circ}$, slice thickness $1 \mathrm{~mm}$ with a noninterpolated voxel size of $1 \times 1 \times 1 \mathrm{~mm}^{3}$.

The hypointensities of the dentate and interposed nuclei were outlined on the magnitude image of the SWI scan as a "Hull" ROI (Fig. 3A). Note, that for creation of the atlas template the space between dentate and interposed nuclei had to be filled. Together with the probability maps 


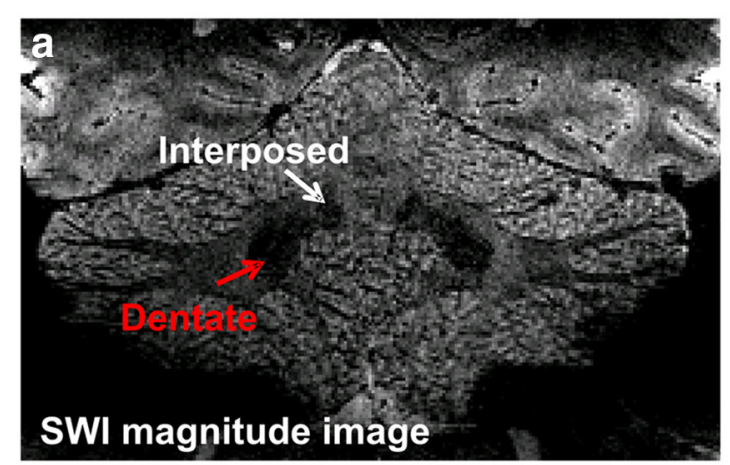

\section{b Top (dorsal) view}
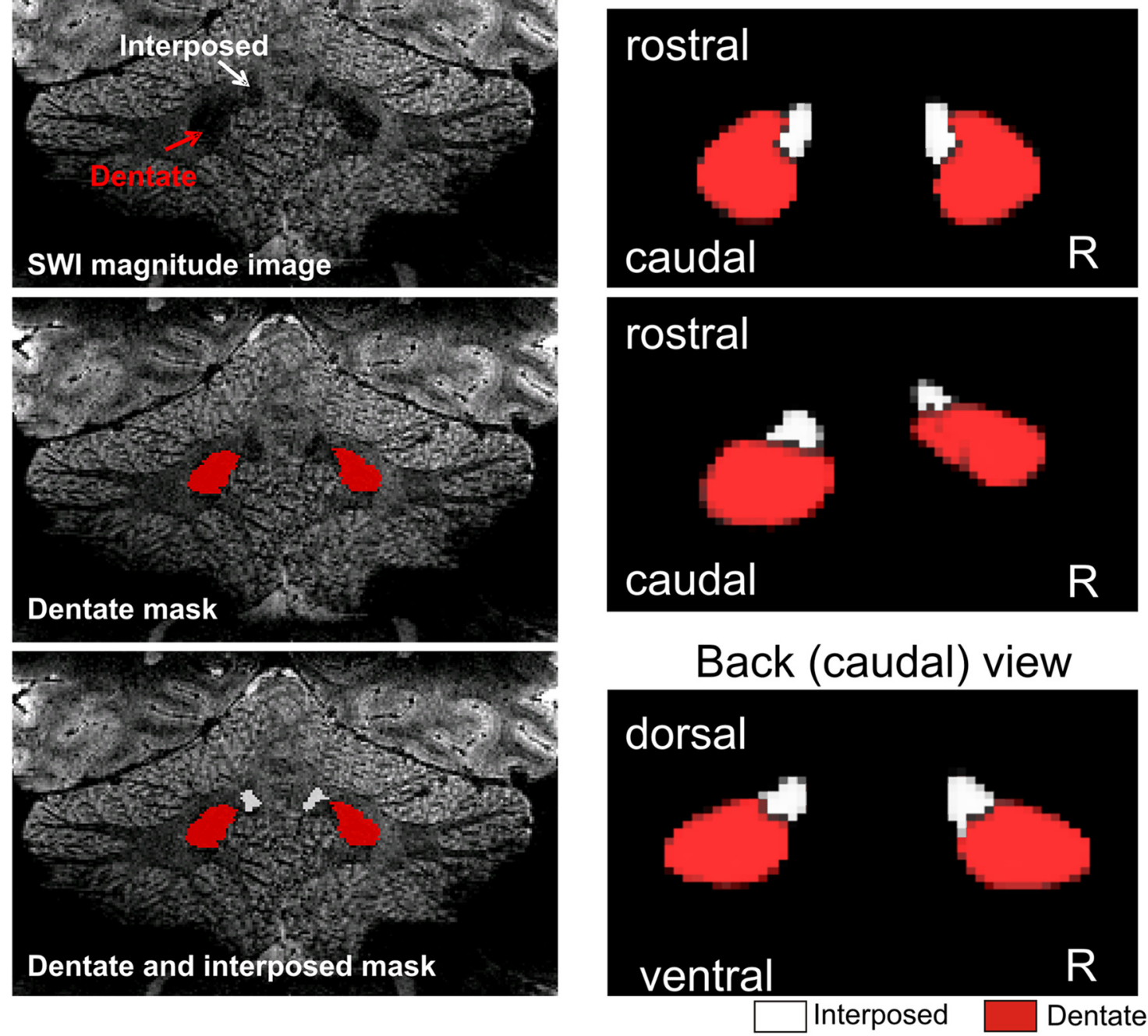

Figure 3. Creation of the new template including dentate and interposed nuclei. $\boldsymbol{a}$, Drawings of the dentate (red) and interposed (white) masks in the SWI magnitude images in an individual subject. Nuclei are seen as hypointensities (top row). $\boldsymbol{b}, 3 \mathrm{D}$-view of new template based on drawings in 24 healthy subjects. Top (dorsal) view is shown from two visual angles. Note that the dentate-interposed template includes both the interposed and dentate nuclei. For illustration purposes, the dentate-interposed template has been superimposed by a dentate-only template (red). R, Right.

obtained from the tissue segmentation, these images were then submitted to the DARTEL algorithm to generate a new group template (Ashburner, 2007). To ensure compatibility with the SUIT atlas, the images were all normalized into SUIT space based on the T1-weighted scans only. The result is a representative template of the position and extent of the bean-shaped dentate plus interposed hypointensities in atlas space (Fig. 3B).

ROI-based spatial normalization of the dentate and interposed nuclei. The dentate and interposed nuclei were identified as hypointensities on the mean EPI images and marked as regions-of-interest (ROIs) using MRIcron-software in each individual subject. They were drawn as one bean-shaped form. For normalization, a modified version of the SUIT method described above was used (Diedrichsen et al., 2011). This normalization algorithm tries to deform the $\mathrm{T} 1$ image so that it fits to the SUIT template, while optimizing the overlap between the ROI and the dentate-interposed template. To avoid activation surrounding the dentate-interposed nuclei being smoothed into the ROI, the functional images were masked with the dentate-interposed ROI before normalization. The normalized functional data from the dentate-interposed nuclei were resampled at $1 \times 1 \times 1 \mathrm{~mm}^{3}$ resolution and then smoothed with a $3 \mathrm{D}$ convolution with an isotropic Gaussian kernel of $4 \mathrm{~mm}$ FWHM. The explicit masking option was used in SPM. SVC was performed using the new dentate-interposed template as ROI.

\section{Results}

Behavioral data

Mean spontaneous blink rate was 30.4 blinks per minute (SD 18.0 ) in the group of all 27 participants. In seven subjects, the total CR incidence (converted to CR incidence per minute) was below the mean group spontaneous blink rate. These subjects were excluded from further behavioral and fMRI analysis.

\section{Unpaired phase}

Participants showed eyeblinks in 91\% (SD 10.98) of the unpaired US-only trials. Figure $2 B$ depicts individual eyelid traces of the 25 trials in one subject, as well as the average trace. Group mean onset of unconditioned eyeblink recordings was $70.01 \mathrm{~ms}$ (SD 13.48). In the unpaired CS-only trials eyeblinks were seen in only $2.4 \%$ (SD 3.28) of the trials in the CS-US time window (Fig. 2B; eyelid traces of the same individual subject). The incidence of 
a

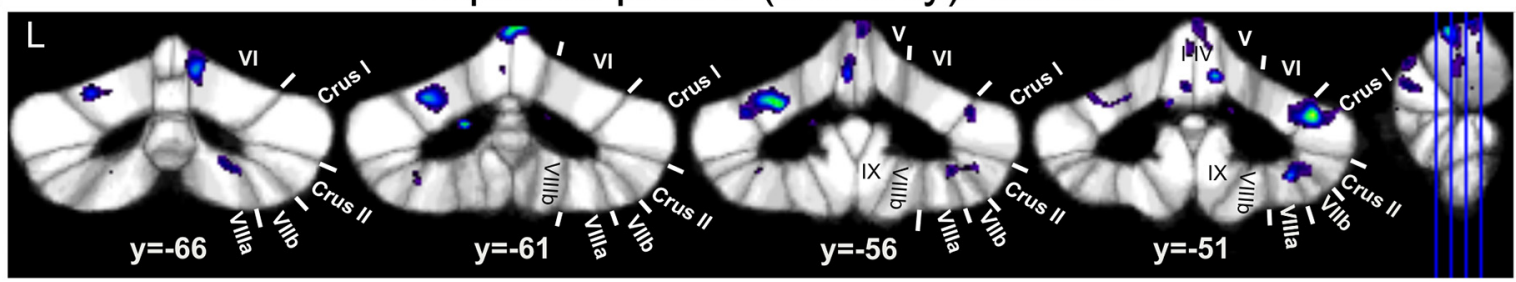

b

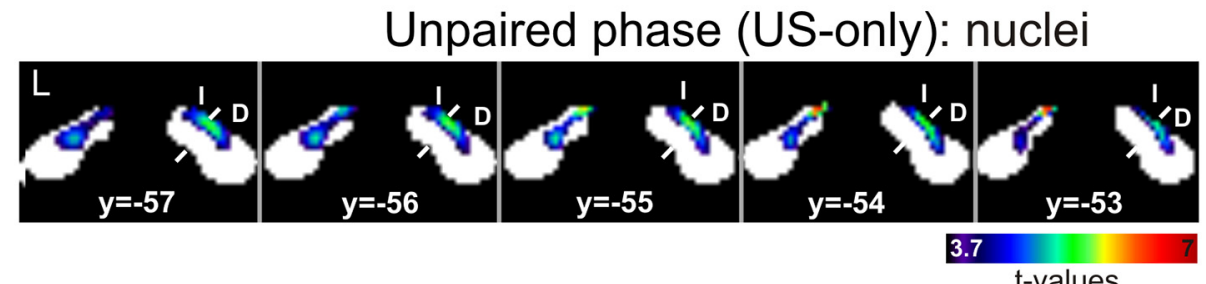

5

t-values
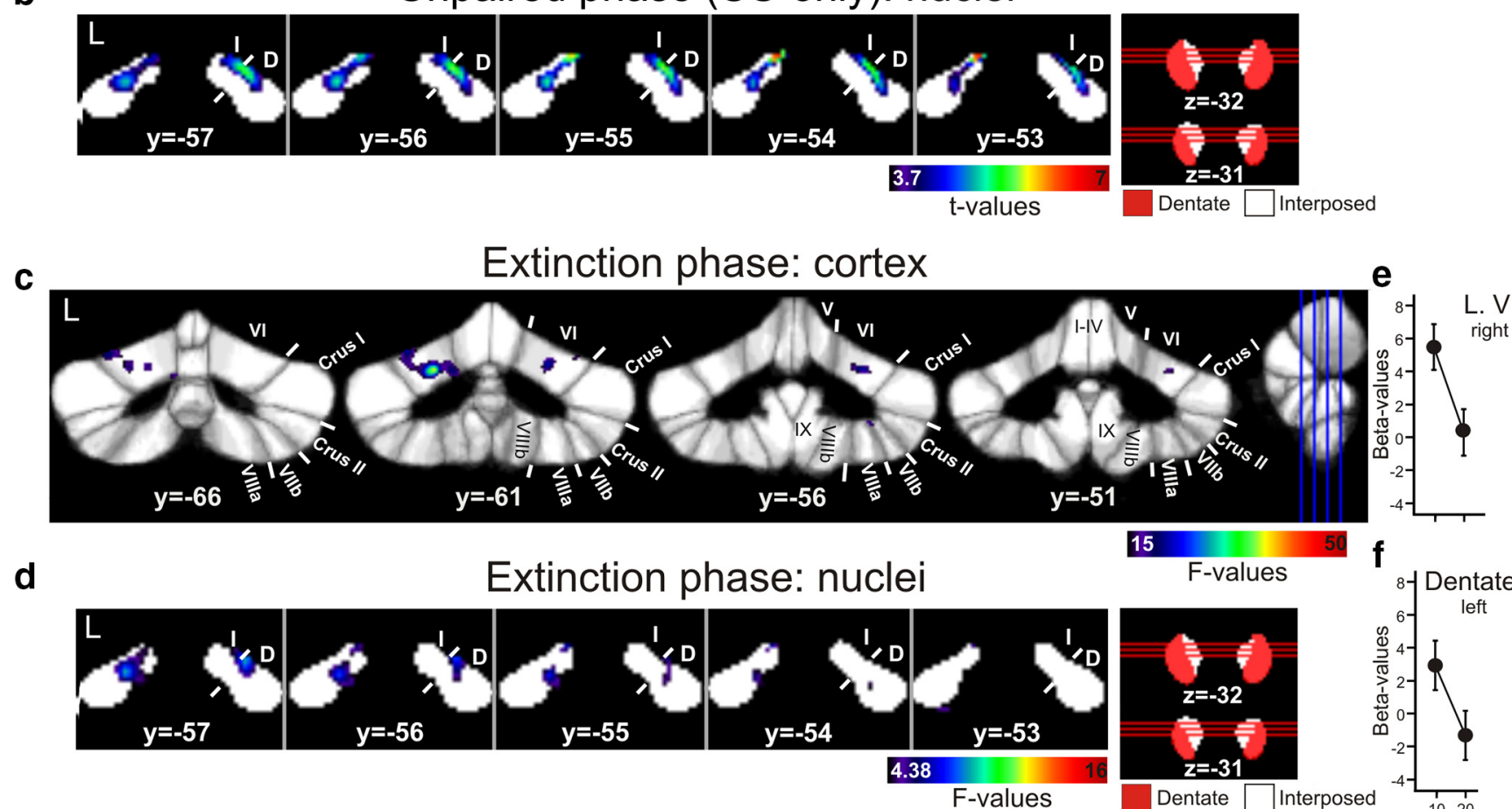

d
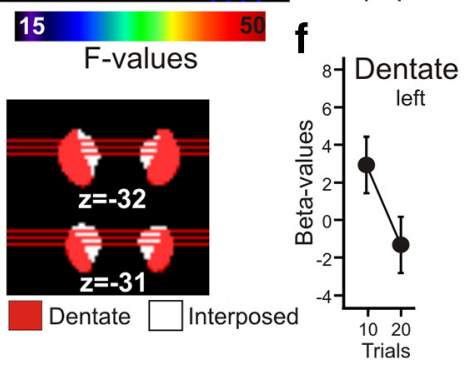

Figure 4. Cerebellar cortical and nuclear activations in US-only trials in the unpaired phase $(\boldsymbol{a}, \boldsymbol{b})$, and in the extinction phase $(\boldsymbol{c}, \boldsymbol{d})$. Unpaired phase is thresholded at $p<0.05$ (permutation corrected; one-sample $t$ tests). Extinction phase is thresholded at a trend level of $p<0.001$ (uncorrected; repeated-measures ANOVA) for cerebellar cortex and $p<0.05$ (uncorrected; repeatedmeasures ANOVA) for cerebellar nuclei. Group mean estimated $\beta$-values and SEs in the two blocks of extinction trials (10 trials per block) are shown for regions of activation in right lobule VI (e) and interposed nucleus $(\boldsymbol{f})$. Activations of the cerebellar lobules are mapped onto coronal slices of the SUIT maximum probability template (Diedrichsen et al., 2009). Positions of slices are indicated in the sagittal view (from $y=-66$ to $y=-51 \mathrm{~mm}$ ). Activations of the cerebellar nuclei are mapped onto coronal slices of the newly developed dentate and interposed template. Positions of slices are indicated in axial views of the dentate-interposed template. For illustration purposes, the dentate-interposed template has been superimposed by a dentate-only template (red). L, Left; $y, z$, SUIT coordinates (in mm); Roman numerals, cerebellar lobules according to Schmahmann et al. (1999); D, dentate; I, interposed.

eyeblinks showed no significant increase across unpaired CSonly trials (block effect considering two blocks of 10 unpaired CS-only trials each: $F_{(1,19)}=0.81, p=0.379$; ANOVA with repeated-measures).

\section{CR acquisition}

Participants showed significant effects of conditioning. Group mean CR incidences and SEs are shown in the top row of Figure $2 C$, individual eyelid traces in the second row, and averaged traces of the same subject in the third row. Paired CS-US trials are shown on the right and CS-only trials interspersed in paired trials on the left. Conditioned responses which start after CS onset and before US onset are clearly seen.

In the group of all subjects significant increase of conditioned responses was observed during CR acquisition. ANOVA with repeated measures showed a significant block effect $\left(F_{(4,76)}=\right.$ $20.78, p<0.001)$. CR incidences increased across the first three blocks of the experiment and plateaued in the second half (Fig. $2 C$ ). The largest increase was found between the second (mean
CR incidence $=30.75 \%$ SD 24.67) and third (56.00\% SD 19.70) block of paired trials.

Likewise, CR incidence in interspersed CS-only trials showed a significant increase during CR acquisition (Fig. 2C). ANOVA with repeated-measures showed a significant block effect $\left(F_{(4,76)}=\right.$ $11.85, p<0.001)$. Again, the largest increase was found between the second (mean CR incidence $=35.00 \%$ SD 28.19) and third block (55.00\% SD 27.43).

\section{CR extinction}

CR incidence declined during the extinction trials. Considering five blocks with five CS-only extinction trials each, ANOVA with repeated measures showed a significant block effect $\left(F_{(4,76)}=\right.$ $6.99, p=0.002$; Greenhouse Geisser corrected). Most prominent decrease was found between the first $(34.00 \%$ SD 31.85$)$ and second (17.00\% SD 22.73) block of five extinction trials. Considering two blocks with 10 CS-only extinction trials each, CR incidence was significantly reduced in the second block $(10.50 \% \mathrm{SD}$ 
Table 1. Summary of activations in the cerebellar cortex: unpaired phase

\begin{tabular}{|c|c|c|c|c|c|}
\hline Condition/contrast & Side & $x, y, z(\mathrm{~mm})$ & Location & Cluster voxel size $\left(\mathrm{mm}^{3}\right)$ & $t$ \\
\hline \multirow[t]{16}{*}{ US-only } & Left & $-8,-44,-22$ & $\underline{\text { I-IV }}$ & 813 & 9.45 \\
\hline & Right & $39,-51,-30$ & $\overline{\text { Crus I, VI }}$ & 1070 & 8.06 \\
\hline & Right & $6,-39,-17$ & $\underline{\underline{I-I V}}$ & 209 & 7.95 \\
\hline & Left & $-27,-56,-26$ & $\overline{\mathrm{VI}}$, Crus I & 1322 & 7.66 \\
\hline & Left & $-18,-70,-22$ & $\underline{\mathrm{V}}$, Crus I & 756 & 7.55 \\
\hline & Left/Right & $7,-65,-15$ & $\underline{\mathrm{V}}, \mathrm{VI}$, Vermis VI & 1547 & 7.16 \\
\hline & Right & $6,-51,-17$ & I-IV & 107 & 6.98 \\
\hline & Right & $31,-51,-50$ & VIIla, VIlb, Crus II & 499 & 6.70 \\
\hline & Right & $9,-74,-42$ & $\underline{\mathrm{VIIb}}$, Crus II & 235 & 5.87 \\
\hline & Right & $16,-66,-46$ & VIIIa, VIIb & 137 & 5.80 \\
\hline & Left & $-18,-71,-48$ & $\underline{\mathrm{VIlb}}$ & 54 & 5.68 \\
\hline & Left/Right & $1,-78,-28$ & Vermis Crus II & 40 & 5.67 \\
\hline & Right & $21,-36,-27$ & I-IV & 17 & 5.63 \\
\hline & Left & $-15,-71,-27$ & $\underline{\mathrm{VI}}$ & 36 & 5.55 \\
\hline & Left & $-33,-59,-49$ & $\underline{\text { Vllb }}$ & 48 & 5.42 \\
\hline & Left & $-23,-74,-21$ & $\underline{\mathrm{VI}}$ & 6 & 5.20 \\
\hline \multirow[t]{2}{*}{ CS-only } & Left & $-7,-74,-32$ & Crus I, VI, Vermis VI, Crus II, Vermis Crus II & 1412 & 8.53 \\
\hline & Left & $-10,-54,-42$ & $\underline{I X}$ & 317 & 7.35 \\
\hline
\end{tabular}

fMRI signal was analysed in US-only and (S-only trials by means of one-sample $t$ test. Statistical results are reported at a height threshold of $p<0.05$ (permutation corrected; $t=5.0$ ). Peak location is underlined. $x, y, z$, SUIT coordinate; Roman numerals indicate cerebellar lobules according to Schmahmann et al. (1999).

Table 2. Summary of activations in the cerebellar cortex: acquisition phase

\begin{tabular}{|c|c|c|c|c|c|}
\hline Condition/contrast & Side & $x, y, z(\mathrm{~mm})$ & Location & Cluster voxel size $\left(\mathrm{mm}^{3}\right)$ & $F$ \\
\hline \multicolumn{6}{|c|}{ CS-US (across 5 blocks of 20 paired trials) } \\
\hline \multirow{21}{*}{ Main cluster of activation } & Left & $-8,-41,-24$ & I-IV & 643 & 20.75 \\
\hline & Right & $9,-50,-26$ & I-IV & 523 & 16.84 \\
\hline & Left & $-5,-65,-15$ & V & 1017 & 15.22 \\
\hline & Right & $8,-65,-15$ & V & 1515 & 28.93 \\
\hline & Left & $-25,-61,-26$ & $\mathrm{VI}$ & 6562 & 38.27 \\
\hline & Right & $33,-54,-30$ & $\mathrm{VI}$ & 6442 & 30.72 \\
\hline & & $5,-75,-16$ & Vermis VI & 1886 & 26.39 \\
\hline & Left & $-11,-78,-29$ & Crus 1 & 5542 & 46.03 \\
\hline & Right & $37,-54,-30$ & Crus I & 1740 & 25.50 \\
\hline & & $9,-76,-30$ & Crus 1 & 356 & 22.95 \\
\hline & & $-4,-79,-28$ & Vermis Crus I & 10 & 21.64 \\
\hline & Left & $-7,-80,-30$ & Crus II & 3325 & 25.89 \\
\hline & Right & $8,-76,-31$ & $\overline{\text { Crus II }}$ & 1446 & 25.11 \\
\hline & & $34,-59,-45$ & Crus II & 150 & 10.58 \\
\hline & & $4,-74,-29$ & Vermis Crus II & 268 & 18.59 \\
\hline & Left & $-15,-71,-44$ & Vllb & 2372 & 22.86 \\
\hline & Right & $24,-71,-45$ & Vllb & 2787 & 22.31 \\
\hline & & $-4,-70,-31$ & Vermis VIllb & 125 & 12.49 \\
\hline & Left & $-20,-68,-51$ & VIIIa & 722 & 13.75 \\
\hline & Right & $23,-66,-47$ & VIIla & 1224 & 17.02 \\
\hline & & $5,-64,-31$ & Vermis VIIlla & 116 & 10.21 \\
\hline \multirow[t]{3}{*}{ Additional clusters of activation } & Right & $12,-59,-46$ & $\underline{I X}, \mathrm{VIIIb}$ & 309 & 12.03 \\
\hline & Left & $-22,-39,-39$ & $\underline{\bar{x}}$ & 48 & 9.83 \\
\hline & Left & $-14,-45,-44$ & $\underline{I X}$ & 32 & 9.36 \\
\hline
\end{tabular}

The main cluster of activation including 38771 voxels. This cluster extended from the anterior to the posterior lobe with a focus in L VI bilaterally. Activations in individual lobules are shown. A repeated-measures ANOVA was applied to asses the effect of time across the five blocks of paired (S-US trials ( 20 trials per block). Statistical results are reported at a height threshold of $p<0.05$ (permutation corrected; $F=7.5$ ).

17.91) compared with the first block $\left(25.50 \%\right.$ SD $21.14 ; t_{(19)}=$ 2.82, $p=0.011$, two-sided paired $t$ test; Figure $2 D)$.

\section{MRI data}

\section{Unpaired phase}

Cerebellar cortical activity in unpaired US-only trials, that is related to the unconditioned eyeblink reflex, was observed in lobule VI bilaterally extending into Crus I (one-sample $t$ test; $p<0.05$, corrected for multiple tests using permutation; Fig. $4 A$ ). Furthermore, activations were present in the anterior lobe. Smaller activations were observed in lobule VIIb bilaterally and extended into lobules Crus II, VIIIA, and VIIIB on the right.
In the cerebellar nuclei activation was present within both interposed nuclei (one-sample $t$ test; $p<0.05$, permutation corrected; Fig. $4 B$ ). Activation extended into the dorsal parts of the dentate nuclei bilaterally.

Cerebellar cortical activity in unpaired CS-only trials, that is related to the tone, was observed in left intermediate and vermal areas extending from lobule VI to Crus II, and in lobule IX (onesample $t$ test; $p<0.05$, corrected for multiple tests using permutation). Areas in lobule VI overlapped with activation in US-only trials. Areas are in good accordance with cerebellar auditory regions based on the animal and human literature (Snider and Stowell, 1944; Pastor et al., 2008; O’Reilly et al., 2010). At a trend 
Table 3. Summary of activations in the cerebellar cortex: extinction phase

\begin{tabular}{|c|c|c|c|c|c|}
\hline Condition/contrast & Side & $x, y, z(\mathrm{~mm})$ & Location & Cluster voxel size $\left(\mathrm{mm}^{3}\right)$ & $F$ \\
\hline \multirow[t]{11}{*}{ CS-only extinction (across 2 blocks of 10 trials) } & Left & $-22,-62,-27$ & $\underline{\mathrm{VI}}$ & 82 & 42.51 \\
\hline & Left & $-25,-75,-46$ & Crus II & 81 & 30.16 \\
\hline & Left & $-8,-78,-27$ & $\overline{\text { Crus I, }}, \mathrm{VI}$ & 110 & 27.94 \\
\hline & Left & $-23,-75,-18$ & $\overline{\mathrm{VI}}$ & 76 & 27.69 \\
\hline & Left & $-6,-81,-39$ & Crus II & 178 & 25.05 \\
\hline & Right & $22,-59,-24$ & $\underline{\mathrm{VI}}$ & 412 & 24.87 \\
\hline & Right & $9,-74,-39$ & Crus II & 70 & 24.44 \\
\hline & Right & $10,-79,-43$ & Crus II & 35 & 20.94 \\
\hline & Right & $29,-55,-47$ & $\underline{\underline{\text { VIIla }}}$ & 10 & 19.61 \\
\hline & Left & $-13,-76,-36$ & Crus II & 9 & 18.42 \\
\hline & Right & $38,-49,-30$ & $\underline{\mathrm{VI}}$ & 14 & 17.87 \\
\hline
\end{tabular}

A repeated-measures ANOVA was applied to assess the effect of time across the two blocks of paired (S extinction trials ( 10 trials per block). Statistical results are reported as trends at a height threshold of $p<0.001$ (uncorrected; $F=15.08$ ). Note that one cluster of 15 voxels was significant at a permutation corrected height threshold of $p<0.05(F=32.5)$ in left lobule VI.

Table 4. Summary of activations in the cerebellar nuclei: unpaired phase

\begin{tabular}{|c|c|c|c|c|c|}
\hline Condition/contrast & Side & $x, y, z(\mathrm{~mm})$ & Location & Cluster voxels size $\left(\mathrm{mm}^{3}\right)$ & $t$ \\
\hline \multirow[t]{4}{*}{ US-only } & Left & $-8,-53,-27$ & Dentate & 357 & 6.37 \\
\hline & & & Interposed & 82 & \\
\hline & Right & $11,-61,-31^{*}$ & Dentate & 310 & 5.64 \\
\hline & & & Interposed & 130 & \\
\hline \multirow[t]{2}{*}{ CS-only } & Left & $-18,-64,-38$ & Dentate & 50 & 4.99 \\
\hline & Left & $-10,-52,-37$ & Dentate & 40 & 4.68 \\
\hline
\end{tabular}

Activity related to US-only and CS-only trials in the unpaired phase. fMRI signal was analyzed in US-only and CS-only trials by means of one-sample $t$ test. Statistical results are reported at a height threshold of $p<0.05$ (permutation corrected; $t=3.7)$. Local maxima of activation are given. Cluster voxel size is given separately for the dentate and interposed nuclei. Peak location is underlined. $x, y, z, S$ UIT coordinates.

*Maximum at the border of dentate and interposed nuclei.

Table 5. Summary of activations in the cerebellar nuclei: acquisition phase and extinction phase

\begin{tabular}{|c|c|c|c|c|c|}
\hline Condition/contrast & Side & $x, y, z(\mathrm{~mm})$ & Location & Cluster voxels size & $F$ \\
\hline \multicolumn{6}{|l|}{ Acquisition phase } \\
\hline \multirow[t]{4}{*}{ CS-US (across 5 blocks of 20 paired trials) } & Right & $11,-53,-28$ & Dentate & 742 & 23.67 \\
\hline & & & Interposed & 207 & \\
\hline & Left & $-8,-53,-27$ & $\overline{\text { Dentate }}$ & 886 & 16.01 \\
\hline & & & Interposed & 222 & \\
\hline \multicolumn{6}{|l|}{ Extinction phase } \\
\hline CS-only extinction (across 2 blocks of 10 trials) & Left & $-14,-60,-32$ & Dentate & 2 & 15.58 \\
\hline
\end{tabular}

Activity related to CR acquisition (top), and activity related to CR extinction (bottom). Local maxima of activation are given. Cluster voxel size is given separately for the dentate and interposed nuclei. Peak location is underlined. $x, y, z$, SUIT coordinates.

Top, A repeated-measures ANOVA was applied to assess the effect of time across the five blocks of paired CS-US trials (20 trials per block). Statistical results are reported at a height threshold of $p<0.05$ (permutation corrected; $F=5.7$ ). Bottom, A repeated-measures ANOVA was applied to assess the effect of time across the two blocks of paired (S extinction trials (10 trials per block). Statistical results are reported as trends at a height threshold of $p<0.001$ (uncorrected; $F=15.08)$.

level ( $p<0.001$, uncorrected) activation was present bilaterally including bilateral lobule VI. In the cerebellar nuclei activation was present within ventral parts of the dentate nucleus (onesample $t$ test; $p<0.05$, permutation corrected: left dentate; $p<$ 0.001 , uncorrected: bilateral dentate). There was no significant effect of time across unpaired CS-only trials within the cerebellar cortex and nuclei ( $p<0.05$, corrected for multiple tests using permutation; repeated-measures ANOVA considering two blocks of 10 unpaired CS-only trials).

Summaries of activation of the cerebellar cortex and nuclei in unpaired US-only and CS-only trials are given in Tables 1 and 4.

\section{Acquisition phase}

A significant effect of time across the five blocks of paired acquisition trials was found in lobule VI bilaterally (repeated-measures ANOVA; $p<0.05$, corrected for multiple tests using permutation; Fig. 5A). Activations extended into anterior lobe, Crus I and Crus II. Additional activations were present in lobules VIIb and VIII. Group mean estimated $\beta$-values and SEs in the five blocks of paired trials are shown for the region of significant activation in right lobule VI in Figure 5C. fMRI signal peaked in block 3 (trials 41-60). Data are summarized in Table 2.

Concomitant activation was found in the cerebellar nuclei. Most prominent activation was present in the interposed nucleus ipsilaterally to the CS (right) with some extension into the dentate nucleus (maximum $F=23.67, x=11, y=-53, z=-28$; $p<0.05$, permutation corrected; Fig. $5 B$ ). In addition, activation was found in the contralateral (i.e., left) interposed and dentate nucleus. Group mean estimated $\beta$-values and SEs in the five blocks of paired trials are shown for the region of significant activation in right interposed nucleus in Figure 5D. Again, fMRI signal was highest in Block 3 (trials 41-60). Data are summarized in Table 5.

\section{Extinction phase}

Activity related to extinction was weak and observed mainly at a trend level. Considering the cerebellar cortex, an effect of time was present across the two blocks of $10 \mathrm{CS}$-only trials in lobule VI bilaterally (repeated-measures ANOVA; $p<0.001$, uncorrected; Fig. $4 C$ ). There were small extensions into Crus I and Crus II 
a

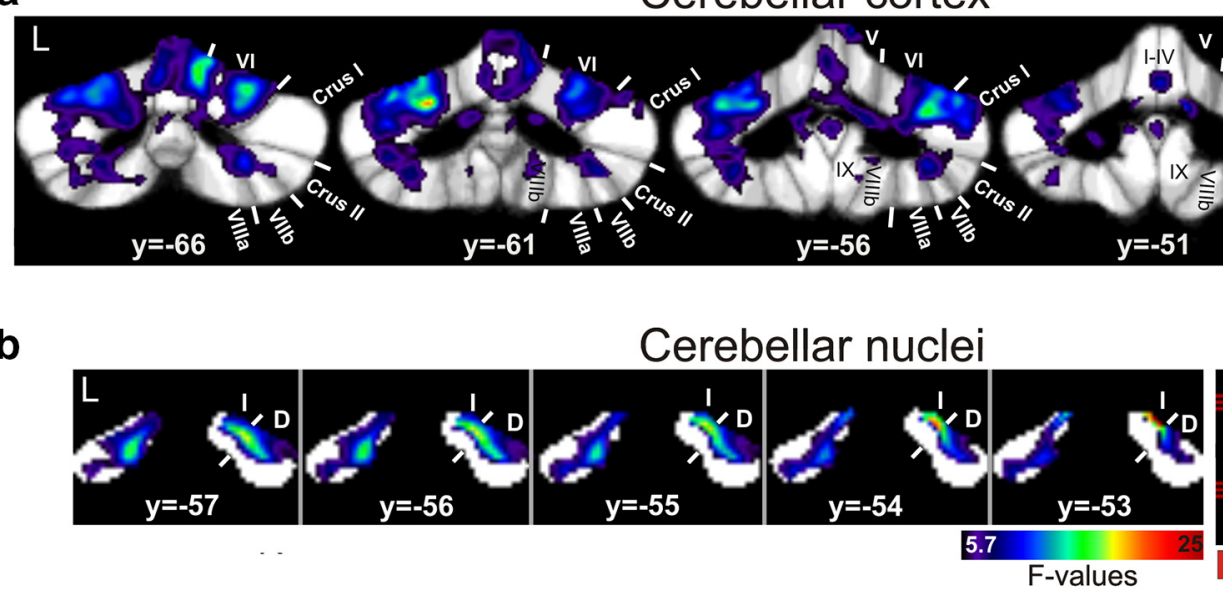

Cerebellar cortex

F-values

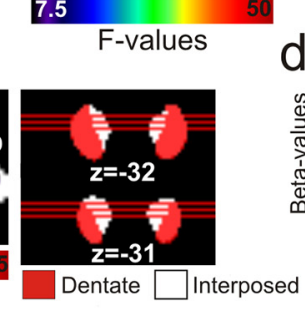

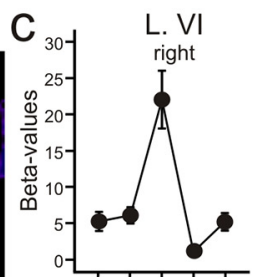

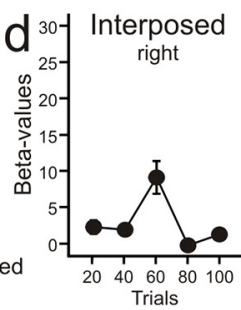

Figure 5. Cerebellar cortical $(\boldsymbol{a})$ and nuclear $(\boldsymbol{b})$ activations in acquisition phase. Effects of time during acquisition are mapped onto coronal slices (a) of the SUIT maximum probability template (Diedrichsen et al., 2009) and (b) of the newly developed dentate and interposed template ( $p<0.05$, permutation corrected). Group mean estimated $\beta$-values and SEs in the five blocks of paired trials are shown for regions of significant activation in right lobule VI (c) and interposed nucleus (d). L, Left; $y$, z, SUIT coordinates (in mm); Roman numerals, cerebellar lobules; D, dentate; I, interposed. See Figure 4 for further explanation.

(data not shown). Only one cluster of 15 voxels was significant at a permutation corrected height threshold of $p<0.05(F=32.5)$ in left lobule VI.

In the cerebellar nuclei, only two voxels in left dentate showed activation above a height threshold of $p<0.001$ (uncorrected). For illustration purposes only, data are shown at a height threshold of $p<0.05$ (uncorrected; $F=4.38$ ) in Figure 4D. Group mean estimated $\beta$-values and SEs in the two blocks of extinction trials are shown for the regions of activation at a height threshold of $p<0.001$ (uncorrected) in right lobule VI (Fig. 4E) and left dentate (Fig. $4 F$ ). Note, that fMRI signal was low already during the first block of 10 extinction trials and showed a further decline in the second block. Data are summarized in Tables 3 and 5.

\section{Discussion}

During early acquisition of conditioned eyeblinks fMRI signals showed a simultaneous increase within the cerebellar cortex and nuclei in humans. Increased activity was most prominent in lobules VI and the interposed nuclei, and overlapped with areas related to performance of the unconditioned eyeblink response. Activity of the cerebellar cortex and nuclei was highest at the first time the maximum number of conditioned eyeblink responses was achieved.

The present findings of acquisition-related coactivations are consistent with the view that the cerebellar cortex and nuclei contribute to early acquisition in a concomitant and likely ongoing synergistic manner. This view diverges from the concept of an active transfer process from the cerebellar cortex to the nuclei (Mauk and Donegan, 1997; Medina et al., 2002). The data rather point toward the necessity of an active reverberating loop between the cerebellar cortex and cerebellar nuclei right at the beginning of the learning process. The current human data are in good accordance with animal recording studies that show learning-related activity of the cerebellar cortex and nuclei from the very beginning of eyeblink conditioning (McCormick and Thompson, 1984b; Berthier and Moore, 1990; Gould and Steinmetz, 1996). The data are further supported by a previous fMRI study in rabbits which also found a concurrent change of activation within lobules VI and interposed nuclei during acquisition of conditioned eyeblink responses (Miller et al., 2003). Only three rabbits were tested and signal intensity change was not sufficient for statistical comparisons. None of these studies, however, can clearly distinguish between activity related to acquisition and expression of the conditioned response.

Current knowledge about the physiology of fMRI (or BOLD) signals allows some inferences about the underlying neuronal changes of the observed increased activations. There is increasing evidence that the fMRI signal mostly reflects synaptic activity, rather than of action potentials of output neurons (Logothetis et al., 2001; Thomsen et al., 2004). More specifically, synaptic input of climbing and mossy fibers, as well as inhibitory interneurons, have been shown to contribute to the fMRI signal in the cerebellar cortex, but not the spiking rate of the Purkinje cells (Lauritzen et al., 2012 for review). A majority of the BOLD signal appears to be driven by the mossy fiber/parallel fiber input (for review, see Diedrichsen et al., 2010). Thus, fMRI is unlikely to detect learning-related changes of Purkinje cell activity. Rather, the findings are consistent with learning-related variations of synaptic activity. For many years, long-term depression (LTD) at the parallel fiber-Purkinje cell synapse has been thought to be the main mechanism underlying motor learning in the cerebellar cortex (Albus, 1971; Linden and Connor, 1993). In LTD, synaptic efficacy of parallel fiber synapses is depressed, and a decrease of BOLD signal would be expected. Thus, our findings of increased fMRI signals cannot be explained by LTD at the parallel fiberPurkinje cell synapse. Today, the LTD hypothesis of learning in the cerebellar cortex is increasingly being challenged (Schonewille et al., 2011; Gao et al., 2012; Hesslow et al., 2013). Evidence is accumulating that learning related plastic changes occur at many places in the granular, molecular, and Purkinje cell layers and are not restricted to the parallel fiber-Purkinje cell synapse. For example, it has been shown that long-term potentiation (LTP) at the mossy fiber to granule cell synapse is important during early learning (Gao et al., 2012). In addition, interneurons that inhibit the Purkinje cells may be involved. These and other mechanisms could explain the observed increased fMRI signal. Note that US-mediated climbing fiber and CS-mediated mossy fiber input cannot explain the observed learning-related change of fMRI signal, because they were present in all acquisition trials. 
Activation in the cerebellar nuclei coincided with the early period of prominent activation in the cerebellar cortex. Although the physiology of the fMRI signal of the cerebellar nuclei has never been studied, it is likely that the same principles apply as for the cerebellar and cerebral cortex. Synaptic activity of Purkinje cell input and collaterals of mossy and climbing fibers are likely candidates to drive the fMRI signals of the cerebellar nuclei, but not spiking of the nuclear cells themselves (Stefanescu et al., 2013). Decreased inhibition of the nuclei due to LTD at the parallel fiber-Purkinje cell synapse is therefore unlikely to explain the present results. Rather, our data are consistent with an additional role of LTP at the mossy fiber to nuclear cell synapse (for review, see Zhang and Linden, 2006; Pugh and Raman, 2008; Freeman and Steinmetz, 2011).

The decrease of the fMRI signal in the cerebellar cortex and nuclei after the maximum number of CRs is achieved is unexpected and needs to be confirmed in future studies. Possible explanations may be decreased mossy fiber input, or less local processing, for example Golgi cells can very quickly damp down mossy fiber input and reduce overall granule cell firing (for review, see D'Angelo and De Zeeuw, 2009).

Present results are in line with previous fMRI studies in humans showing increased fMRI signal in the cerebellar cortex as a result of learning (Ramnani et al., 2000; Cheng et al., 2008, 2014). Miller et al. (2003) found an acquisition-related fMRI signal decrease in bilateral lobule VI in rabbits. Previous positron emission tomography (PET) studies in humans showed both increases of regional cerebral blood flow (rCBF; Blaxton et al., 1996; Parker et al., 2012) and glucose metabolism (Logan and Grafton, 1995), as well as decreases of rCBF (Molchan et al., 1994; Schreurs et al., 1997, 2001; Parker et al., 2012). Based on the present findings the assessment time during the course of learning is crucial. Maximum increase of activity was observed at the first time the maximum number of CRs was achieved, and the activity increase may be missed in case measurement is done outside this critical interval. Findings by Miller et al. (2003) may also be different because learning rates are significantly slower in rabbits compared with humans (Moore, 2001).

Previous neuroimaging studies in humans have not been able to show consistent activation of the interposed nuclei at a high spatiotemporal resolution, probably because of methodological constrains at lower magnetic field and lack of more advanced normalization techniques. There is one PET study which reported increased activation of the cerebellar nuclei (Logan and Grafton, 1995). However, spatial resolution was low and no conclusion could be drawn on the level of individual nuclei. A more recent fMRI study reported a positive correlation between behavioral learning rate and activation of the dentate nuclei, but no learning-related activation of the cerebellar nuclei (Cheng et al., 2014). They used a less advanced normalization method. Very similar to our findings, Miller et al. (2003) found an increase of BOLD signal in the interposed nuclei during early acquisition in rabbits.

The distribution of cortical cerebellar activation related to acquisition of conditioned eyeblinks and performance of the unconditioned eyeblinks are in very good accordance with findings in the animal and human literature. Similar to the present findings, two main regions in the posterior lobe bilaterally were found to be related to unconditioned eyeblinks in a previous $1.5 \mathrm{~T} \mathrm{fMRI}$ study, one in lobule VI and Crus I, and the other in lobules Crus II-VIIIa (Dimitrova et al., 2002). These eyeblink-related areas agree with blink reflex control areas shown in previous animal studies (Hesslow, 1994). Regarding acquisition of conditioned eyeblinks, lobule VI is known to be of major importance (Yeo et al., 1985; Ramnani et al., 2000; Cheng et al., 2008). In their early studies, Hardiman and Yeo (1992) reported that in addition to lobule VI, lobules Crus I and Crus II contribute to CR acquisition. Likewise, human cerebellar lesion studies show that lobule VI and Crus I are important in acquisition of conditioned eyeblink responses (Gerwig et al., 2003). As in the present study, most PET and fMRI studies in healthy human subjects show more extended areas of activation bilaterally including also parts of the anterior lobe, lobule VIIB and lobule VIII (Blaxton et al., 1996; Cheng et al., 2014). A more extended cerebellar network appears to be involved in acquisition of conditioned eyeblink responses, although only lesions of lobule VI and adjacent Crus I ipsilateral to the US are followed by significant reduction of learning ability. Given the activation of more lateral parts of the cerebellar hemisphere, additional activation of the dentate nuclei may not be surprising.

PET studies suggest that partly overlapping areas in the cerebellar cortex support acquisition and extinction in humans (Schreurs et al., 1997, 2001; Parker et al., 2012). Our findings agree with these observations. During extinction, however, activation of the cerebellar cortex and nuclei was seen only at a trend level. Extinction occurred primarily within the first 10 extinction trials, and the extinction period may have been too short to acquire sufficient $\mathrm{fMRI}$ signal. To exclude the latter, extinction rate should be slowed in future studies by including more CS-only trials in the acquisition phase.

In summary, our data support a simultaneous and synergistic, two-site model of cerebellar learning that involves both the cerebellar cortex and cerebellar nuclei. Both lobule VI and interposed nuclei are of major importance in initial eyeblink conditioning. Because fMRI signal was increased during early acquisition, is appears unlikely that LTD is the sole factor in the underlying plasticity of the cerebellar cortex. Increased fMRI signal in the cerebellar cortex and nuclei is consistent with LTP.

\section{References}

Albus J (1971) A theory of cerebellar function. Math Biosci 10:25-61. CrossRef

Ashburner J (2007) A fast diffeomorphic image registration algorithm. Neuroimage 38:95-113. CrossRef Medline

Berthier NE, Moore JW (1990) Activity of deep cerebellar nuclear cells during classical conditioning of nictitating membrane extension in rabbits. Exp Brain Res 83:44-54. Medline

Blaxton TA, Zeffiro TA, Gabrieli JD, Bookheimer SY, Carrillo MC, Theodore WH, Disterhoft JF (1996) Functional mapping of human learning: a positron emission tomography activation study of eyeblink conditioning. J Neurosci 16:4032-4040. Medline

Bracha V, Zhao L, Wunderlich DA, Morrissy SJ, Bloedel JR (1997) Patients with cerebellar lesions cannot acquire but are able to retain conditioned eyeblink reflexes. Brain 120:1401-1413. CrossRef Medline

Bracha V, Zhao L, Irwin K, Bloedel JR (2001) Intermediate cerebellum and conditioned eyeblinks: parallel involvement in eyeblinks and tonic eyelid closure. Exp Brain Res 136:41-49. CrossRef Medline

Bracha V, Zbarska S, Parker K, Carrel A, Zenitsky G, Bloedel JR (2009) The cerebellum and eye-blink conditioning: learning versus network performance hypotheses. Neuroscience 162:787-796. CrossRef Medline

Cheng DT, Disterhoft JF, Power JM, Ellis DA, Desmond JE (2008) Neural substrates underlying human delay and trace eyeblink conditioning. Proc Natl Acad Sci U S A 105:8108-8113. CrossRef Medline

Cheng DT, Meintjes EM, Stanton ME, Desmond JE, Pienaar M, Dodge NC, Power JM, Molteno CD, Disterhoft JF, Jacobson JL, Jacobson SW (2014) Functional MRI of cerebellar activity during eyeblink classical conditioning in children and adults. Hum Brain Mapp 35:1390-1403. CrossRef Medline

Christian KM, Thompson RF (2003) Neural substrates of eyeblink condi- 
tioning: acquisition and retention. Learn Mem 10:427-455. CrossRef Medline

Cooke SF, Attwell PJ, Yeo CH (2004) Temporal properties of cerebellardependent memory consolidation. J Neurosci 24:2934-2941. CrossRef Medline

D'Angelo E, De Zeeuw CI (2009) Timing and plasticity in the cerebellum: focus on the granular layer. Trends Neurosci 32:30-40. CrossRef Medline

Diedrichsen J (2006) A spatially unbiased atlas template of the human cerebellum. Neuroimage 33:127-138. CrossRef Medline

Diedrichsen J, Balsters JH, Flavell J, Cussans E, Ramnani N (2009) A probabilistic MR atlas of the human cerebellum. Neuroimage 46:39-46. CrossRef Medline

Diedrichsen J, Verstynen T, Schlerf J, Wiestler T (2010) Advances in functional imaging of the human cerebellum. Curr Opin Neurol 23:382-387. CrossRef Medline

Diedrichsen J, Maderwald S, Küper M, Thürling M, Rabe K, Gizewski ER, Ladd ME, Timmann D (2011) Imaging the deep cerebellar nuclei: a probabilistic atlas and normalization procedure. Neuroimage 54:17861794. CrossRef Medline

Dimitrova A, Weber J, Maschke M, Elles HG, Kolb FP, Forsting M, Diener HC, Timmann D (2002) Eyeblink-related areas in human cerebellum as shown by fMRI. Hum Brain Mapp 17:100-115. CrossRef Medline

Dimitrova A, Gerwig M, Brol B, Gizewski ER, Forsting M, Beck A, Aurich V, Kolb FP, Timmann D (2008) Correlation of cerebellar volume with eyeblink conditioning in healthy subjects and in patients with cerebellar cortical degeneration. Brain Res 1198:73-84. CrossRef Medline

Doyon J, Song AW, Karni A, Lalonde F, Adams MM, Ungerleider LG (2002) Experience-dependent changes in cerebellar contributions to motor sequence learning. Proc Natl Acad Sci U S A 99:1017-1022. CrossRef Medline

Eklund A, Andersson M, Knutsson H (2012) fMRI analysis on the GPUpossibilities and challenges. Comput Methods Programs Biomed 105: 145-161. CrossRef Medline

Freeman JH, Steinmetz AB (2011) Neural circuitry and plasticity mechanisms underlying delay eyeblink conditioning. Learn Mem 18:666-677. CrossRef Medline

Friston KJ, Frith CD, Turner R, Frackowiak RS (1995) Characterizing evoked hemodynamics with fMRI. Neuroimage 2:157-165. CrossRef Medline

Gao Z, van Beugen BJ, De Zeeuw CI (2012) Distributed synergistic plasticity and cerebellar learning. Nat Rev Neurosci 13:619-635. CrossRef Medline

Gerwig M, Dimitrova A, Kolb FP, Maschke M, Brol B, Kunnel A, Böring D, Thilmann AF, Forsting M, Diener HC, Timmann D (2003) Comparison of eyeblink conditioning in patients with superior and posterior inferior cerebellar lesions. Brain 126:71-94. CrossRef Medline

Glover GH, Li TQ, Ress D (2000) Image-based method for retrospective correction of physiological motion effects in fMRI: RETROICOR. Magn Reson Med 44:162-167. CrossRef Medline

Gormezano I, Kehoe EJ (1975) Classical conditioning: some methodicalconceptual issues. In: Handbook of learning and cognitive processes, Vol 2 (Estes WK, ed), pp 143-179. Hillsdale, NJ: Lawrence Erlbaum.

Gould TJ, Steinmetz JE (1996) Changes in rabbit cerebellar cortical and interpositus nucleus activity during acquisition, extinction, and backward classical eyelid conditioning. Neurobiol Learn Mem 65:17-34. CrossRef Medline

Habas C (2010) Functional imaging of the deep cerebellar nuclei: a review. Cerebellum 9:22-28. CrossRef Medline

Hardiman MJ, Yeo CH (1992) The effect of kainic acid lesions of the cerebellar cortex on the conditioned nictitating membrane response in the rabbit. Eur J Neurosci 4:966-980. CrossRef Medline

Hesslow G (1994) Correspondence between climbing fibre input and motor output in eyeblink-related areas in cat cerebellar cortex. J Physiol 476: 229-244. Medline

Hesslow G, Jirenhed DA, Rasmussen A, Johansson F (2013) Classical conditioning of motor responses: what is the learning mechanism? Neural Netw 47:81-87. CrossRef Medline

Kassardjian CD, Tan YF, Chung JY, Heskin R, Peterson MJ, Broussard DM (2005) The site of a motor memory shifts with consolidation. J Neurosci 25:7979-7985. CrossRef Medline

Lauritzen M, Mathiesen C, Schaefer K, Thomsen KJ (2012) Neuronal inhibition and excitation, and the dichotomic control of brain hemodynamic and oxygen responses. Neuroimage 62:1040-1050. CrossRef Medline
Linden DJ, Connor JA (1993) Cellular mechanisms of long-term depression in the cerebellum. Curr Opin Neurobiol 3:401-406. CrossRef Medline

Logan CG, Grafton ST (1995) Functional anatomy of human eyeblink conditioning determined with regional cerebral glucose metabolism and positron-emission tomography. Proc Natl Acad Sci U S A 92:7500-7504. CrossRef Medline

Logothetis NK, Pauls J, Augath M, Trinath T, Oeltermann A (2001) Neurophysiological investigation of the basis of the fMRI signal. Nature 412: 150-157. CrossRef Medline

Longley M, Yeo CH (2014) Distribution of neural plasticity in cerebellumdependent motor learning. Prog Brain Res 210:79-101. CrossRef Medline

Maderwald S, Thürling M, Küper M, Theysohn N, Müller O, Beck A, Aurich V, Ladd ME, Timmann D (2012) Direct visualization of cerebellar nuclei in patients with focal cerebellar lesions and its application for lesionsymptom mapping. Neuroimage 63:1421-1431. CrossRef Medline

Manto M, Bower JM, Conforto AB, Delgado-García JM, da Guarda SN, Gerwig M, Habas C, Hagura N, Ivry RB, Mariën P, Molinari M, Naito E, Nowak DA, Oulad Ben Taib N, Pelisson D, Tesche CD, Tilikete C, Timmann D (2012) Consensus paper: roles of the cerebellum in motor control-the diversity of ideas on cerebellar involvement in movement. Cerebellum 11:457-487. CrossRef Medline

Mauk MD, Donegan NH (1997) A model of Pavlovian eyelid conditioning based on the synaptic organization of the cerebellum. Learn Mem 4:130 158. CrossRef Medline

McCormick DA, Thompson RF (1984a) Cerebellum: essential involvement in the classically conditioned eyelid response. Science 223:296-299. CrossRef Medline

McCormick DA, Thompson RF (1984b) Neuronal responses of the rabbit cerebellum during acquisition and performance of a classically conditioned nictitating membrane-eyelid response. J Neurosci 4:2811-2822. Medline

Medina JF, Repa JC, Mauk MD, LeDoux JE (2002) Parallels between cerebellum- and amygdala-dependent conditioning. Nat Rev Neurosci 3:122-131. CrossRef Medline

Miller MJ, Chen NK, Li L, Tom B, Weiss C, Disterhoft JF, Wyrwicz AM (2003) fMRI of the conscious rabbit during unilateral classical eyeblink conditioning reveals bilateral cerebellar activation. J Neurosci 23:1175311758. Medline

Molchan SE, Sunderland T, McIntosh AR, Herscovitch P, Schreurs BG (1994) A functional anatomical study of associative learning in humans. Proc Natl Acad Sci U S A 91:8122-8126. CrossRef Medline

Moore JW (2001) A neuroscientist's guide to classical conditoning. New York, Berlin, Heidelberg: Springer.

Oldfield RC (1971) The assessment and analysis of handedness: the Edinburgh inventory. Neuropsychologia 9:97-113. CrossRef Medline

O’Reilly JX, Beckmann CF, Tomassini V, Ramnani N, Johansen-Berg H (2010) Distinct and overlapping functional zones in the cerebellum defined by resting state functional connectivity. Cereb Cortex 20:953-965. CrossRef Medline

Parker KL, Andreasen NC, Liu D, Freeman JH, Ponto LL, O'Leary DS (2012) Eyeblink conditioning in healthy adults: a positron emission tomography study. Cerebellum 11:946-956. CrossRef Medline

Pastor MA, Vidaurre C, Fernández-Seara MA, Villanueva A, Friston KJ (2008) Frequency-specific coupling in the cortico-cerebellar auditory system. J Neurophysiol 100:1699-1705. CrossRef Medline

Pugh JR, Raman IM (2008) Mechanisms of potentiation of mossy fiber EPSCs in the cerebellar nuclei by coincident synaptic excitation and inhibition. J Neurosci 28:10549-10560. CrossRef Medline

Ramnani N, Toni I, Josephs O, Ashburner J, Passingham RE (2000) Learning- and expectation-related changes in the human brain during motor learning. J Neurophysiol 84:3026-3035. Medline

Raymond JL, Lisberger SG, Mauk MD (1996) The cerebellum: a neuronal learning machine? Science 272:1126-1131. CrossRef Medline

Schmahmann JD, Doyon J, McDonald D, Holmes C, Lavoie K, Hurwitz AS, Kabani N, Toga A, Evans A, Petrides M (1999) Three-dimensional MRI atlas of the human cerebellum in proportional stereotaxic space. Neuroimage 10:233-260. CrossRef Medline

Schonewille M, Gao Z, Boele HJ, Veloz MF, Amerika WE, Simek AA, De Jeu MT, Steinberg JP, Takamiya K, Hoebeek FE, Linden DJ, Huganir RL, De Zeeuw CI (2011) Reevaluating the role of LTD in cerebellar motor learning. Neuron 70:43-50. CrossRef Medline

Schreurs BG, McIntosh AR, Bahro M, Herscovitch P, Sunderland T, Molchan 
SE (1997) Lateralization and behavioral correlation of changes in regional cerebral blood flow with classical conditioning of the human eyeblink response. J Neurophysiol 77:2153-2163. Medline

Schreurs BG, Bahro M, Molchan SE, Sunderland T, McIntosh AR (2001) Interactions of prefrontal cortex during eyeblink conditioning as a function of age. Neurobiol Aging 22:237-246. CrossRef Medline

Shutoh F, Ohki M, Kitazawa H, Itohara S, Nagao S (2006) Memory trace of motor learning shifts transsynaptically from cerebellar cortex to nuclei for consolidation. Neuroscience 139:767-777. CrossRef Medline

Snider RS, Stowell A (1944) Receiving areas of the tactile, auditory, and visual systems in the cerebellum. J Neurophysiol 7:331-357.

Stefanescu MR, Thürling M, Maderwald S, Wiestler T, Ladd ME, Diedrichsen J, Timmann D (2013) A 7T fMRI study of cerebellar activation in sequential finger movement tasks. Exp Brain Res 228:243-254. CrossRef Medline

Thompson RF, Steinmetz JE (2009) The role of the cerebellum in classical conditioning of discrete behavioral responses. Neuroscience 162:732755. CrossRef Medline

Thomsen K, Offenhauser N, Lauritzen M (2004) Principal neuron spiking: neither necessary nor sufficient for cerebral blood flow in rat cerebellum. J Physiol 560:181-189. CrossRef Medline

Thürling M, Küper M, Stefanescu R, Maderwald S, Gizewski ER, Ladd ME,
Timmann D (2011) Activation of the dentate nucleus in a verb generation task: a 7T MRI study. Neuroimage 57:1184-1191. CrossRef Medline

Timmann D, Konczak J, Ilg W, Donchin O, Hermsdörfer J, Gizewski ER, Schoch B (2009) Current advances in lesion-symptom mapping of the human cerebellum. Neuroscience 162:836-851. CrossRef Medline

Winkler AM, Ridgway GR, Webster MA, Smith SM, Nichols TE (2014) Permutation inference for the general linear model. Neuroimage 92:381-397. CrossRef Medline

Woodruff-Pak DS, Papka M, Ivry RB (1996) Cerebellar involvement in eyeblink classical conditioning in humans. Neuropsychology 10:443-458. CrossRef

Wrede KH, Johst S, Dammann P, Umutlu L, Schlamann MU, Sandalcioglu IE, Sure U, Ladd ME, Maderwald S (2012) Caudal image contrast inversion in MPRAGE at 7 tesla: problem and solution. Acad Radiol 19:172178. CrossRef Medline

Yeo CH, Hardiman MJ, Glickstein M (1985) Classical conditioning of the nictitating membrane response of the rabbit: III. Connections of cerebellar lobule HVI. Exp Brain Res 60:114-126. CrossRef Medline

Zhang W, Linden DJ (2006) Long-term depression at the mossy fiber-deep cerebellar nucleus synapse. J Neurosci 26:6935-6944. CrossRef Medline 